\title{
CARE COORDINATION LETTER IN PSYCHOGENIC NON- EPILEPTIC SEIZURES WORKS - CASE REPORT
}

\author{
Katarína Hubčíková ${ }^{1,2}$, Tomáš Rakúis ${ }^{1,2}$, Lucia Bruncvik ${ }^{2,3}$, Zuzana Pechanová ${ }^{1,2}$ \& Jitka Bušková ${ }^{2,4}$ \\ ${ }^{1}$ Department of Neuropsychiatry of Slovac Medical University in Bratislava and Psychiatric Hospital \\ of Philipp Pinel in Pezinok, Bratislava, Slovakia \\ ${ }^{2}$ Third faculty of medicine, Charles University in Prague, Prague, Czech Republic \\ ${ }^{3}$ Landesklinikum, Hainburg, Austria \\ ${ }^{4}$ National Institute of Mental Health Czech republic, Klecany, Czech Republic
}

received: 5.1.2021;

revised: 14.3.2021;

accepted: 28.3.2021

$* * * * *$

\section{INTRODUCTION}

Psychogenic nonepileptic seizures (PNES) present a specific diagnosis which demands the inevitable interdisciplinary coordination of patient's health care (diagnosis determination using long-term video-EEG monitoring in epileptological centers and subsequent psychiatric/psychotherapeutic long-term treatment). The coordination turned out problematic in the clinical praxis (Alitalib 2016). The most severe morbidity of the PNES patients is caused by inappropriate medical interventions supposing these are epilepsy seizures. Inappropriate pharmacologic treatment also means side effects of chronic antiepileptic medication (weight gain, hair loss, idiosyncratic reactions, teratogenity). Wrong diagnostic conclusion of PNES status for epileptic leads to groundless aggressive parenteral administration of antipeileptics, endotracheal intubation, coma initiation with general anaesthesia and artificial lung ventilation (Ramos \& Brull 2013). Emergency doctors and non-neurologist resp. non-epileptologist specialist doctors do not necessarily have the experience to differentiate PNES from an epileptic seizure. They do not know, that diagnosis of PNES has already been established, therefore, the more severe, epileptic therapy is initiated (Ramos \& Brull 2013). Reevaluation of PNES diagnosis, inconsistent specialist conclusions and failure of the first provided psychoeducational program complicate the psychotherapeutic treatment and weaken the patient's cooperation (Tolchin 2018). Current trends in the PNES treatment draw attention to quality seizure management in the home environment without the need of emergency medical service (Duncan \& Oto 2018, La France et al 2013). One of the ways to educate the family, caregivers and medical specialists of the primary care about the basic difference between PNES and epilepsy seizures with recommended PNES procedures, is a care coordination letter in PNES (Doss 2018). If the patient manifests new kind of seizure a new video EEG examination should be indicated to guarantee trust in the diagnosis (Duncan \& Oto 2018, La France 2013).

\section{CASE}

The presented case study deals with the impact of sending a coordination letter regarding the health care of a female patient with a 20 -years of dg. PNES determination latency. PNES diagnosis was determined by long-term video-EEG examination. Previously, the patient had been diagnosed for an epilepsy with repeated treatment of "status epilepticus". The patient accepted the psychogenic background of the seizures as well as the recommended systematic psychotherapy. Nevertheless, the patient was repeatedly re-hospitalized for "status epilepticus" by emergency medical service called by by-standers in the street or in public transport, as well as by other specialist doctors during the planned medical check-ups.

The coordination letter, inspired by Doss et al. (2008), was extended by the authors of the presented paper with another important information, such as short history of seizures with information about already realized long term video-EEG monitoring, explanation of common pattern of iatrogenisation in PNES with possible solutions, information about outgoing systematic psychotherapy, description of patient's other dissociative symptoms, detailed description of patient's seizure and recommendations about specific stopping technique for seizures (Figure 1). With a patient's informed consent, a copy of the coordination letter was sent to the patient's primary doctors (general practitioner, gynaecologist, dentist, psychiatrist) and one copy of the letter was always carried by the patient.

After approximately 9 months' time, feedback from the addressed doctors was obtained by telephone call. They were asked the following questions:

- Before receiving this letter, had you known the patient has been lege artis diagnosed with PNES?

- How had you reacted to the patient's seizures before receiving this coordination letter?

- How do you react to the seizures after the education by this coordination letter?

- Do you consider this letter as useful/useless? Why? 
Dear colleagues,

We would like to address you, with the consent of our patient born ...................., to provide you a brief summary and recommendations regarding her/his seizures.

A The patient has been repeatedly hospitalised on our department since ............ She/he has had her/his epileptic seizures treated since .......... (year), including status epilepticus (with admission to ICU) with progressively rising suspicion of converse seizures (psychogenic genesis), at least as comorbidity. Supplemented long term videoEEG (when and where) excluded an epileptic genesis. During the recording, (count) seizures (habitual for patient) were recorded of average duration minutes with absolutely no EEG correlate.

B It is quite common and comprehensible that an emergency doctor (or other specialist) does not have the complete personal history of the patient available or does not have the experience to distinguish PNES from an epileptic seizure. For these reasons, the more severe - epileptic condition is assumed and the treatment of status epilepticus is initiated. According to experts in PNES problematic ${ }^{2,3}$, the most effective way to avoid confusion is a careful education of the family and primary care medicians about appropriate procedure when seizure occurs. If the patient develops new art of seizure a new video EEG examination will be indicated.

C In a long-term therapy - systematic psychotherapy - the patient is shown a motivation and the progress within the realm of possibilities of the therapy. But it is common and expactable that seizures will also occur during this outgoing long process.

D Seizures of the patient have a dramatic course; therefore, a description is enclosed - how the seizures were recorded and described during the long-term video-EEG where the epileptic aetiology was excluded. It should be stated that, apart from the above-mentioned seizures, the PNES patient suffers from various dissociative motoric disorders, as well as from regression manifestations, which disappear spontaneously within a couple of minutes to hours.

E Description of patient's seizure: (including duration)

F Recommended procedure: during patient's seizure:

- provide a safe and secure environment (a mat under the head, minimize a chaos - exaggerated alarm reaction from surrounding people tends to prolong the seizure duration)

- assure the patient that there is no danger, inform her/him where she/he is, stabilise her/him in this acute situation

- direct her/him on regular breathing

- if the seizure persists consider an empty i.m. injection or other painful stimulus (patient knows there is no effective medication, however, the intense stimulus helps to interrupt the dissociative state)

- if the dissociative symptomatic still persists it is optimal to turn onto the assigned caregiver whose availability is being organised and who should accompany the patient by all planned medical terms

In case of interest do not hesitate to contact us.

In ................................ date................... name and signature of the doctor

Patient's permission with providing of this information

References:

1 Doss JL et al.: Appendix: Care coordination treatment plans for patients with psychogenic nonepileptic seizures (PNES). In: LaFrance WC,

Schachter SC. Gates and Rowan's none-pileptic seizures. 4th ed. 380-382. Cambridge: Cambridge University Press, 2018.

${ }^{2}$ LaFrance WC et al.: Management of psychogenic nonepileptic seizures. Epilepsia 2013; $54: 53$ - 67.

3 Duncan R \& Oto M: Managing psychogenic nonepileptic seizures in patients with comorbid epilepsy. In: LaFrance, WC, Schachter SC (eds.).

Gates and Rowans Nonepileptic Seizures, . 262-267. Cambridge: Cambridge University Press, 2018.

A - short history of seizures with information about already realized long term video EEG monitoring, B - explanation of common pattern of iatrogenisation in PNES with possible solutions, C - information about outgoing systematic psychotherapy, D - description of patient's others dissociative symptoms , E- detail description of patient's seizure, $F$ - recommendation about stopping technique for seizures

PNES - psychogenic non-epileptic seizures, ICU - intensive care unit, EEG - electroencephalography

Figure 1. Care coordination letter in psychogenic non-epileptic seizure (adapted from Doss et al. 2008) 
Number of hospitalisation after establishing diagnosis PNES by video-EEG monitoring ( 5 hospitalisations in an intensive care unit with treatment of status "epilepticus, 4 psychiatric hospitalisations) and before receiving the coordination letter (1 hospitalization in intensive care unit (emergency medical service was called by by-standers), 2 psychiatric hospitalizations) were also compared. We also evaluated number of psychotherapeutic session in ambulatory psychotherapist session after establishing diagnosis PNES by video-eeg monitoring and before receiving the letter ( 7 sessions) and number of psychotherapeutic session in ambulatory psychotherapist session after establishing diagnosis PNES by video-eeg monitoring and after receiving the letter (18 sessions).

Patient's dentist and gynaecologist had not have the information that the patient's seizures were reclassified from epileptic to psychogenic, they called emergency medical service for each attack, the doctors limited patient's controls to non-invasive procedures (also taking into account the patient's request). The general practitioner and the psychiatrist had tried to manage the seizures individually before receiving the coordination letter. However, when the patient's seizure lasted over 25 minutes and the administered diazepam did not help, they called emergency medical service. All questioned doctors appreciated that thanks to the coordination letter they learned more about PNES, are less anxious about PNES patient visits, managed own invasive procedures, implemented stop techniques recommended in the letter for managing the PNES attack. If dissociative symptoms persisted even after observation and the patient was unaccompanied, psychiatric hospitalization was indicated instead of the calling emergency medical services.

\section{DISCUSSION}

Patient in our presented study encouters different approaches and procedures - as a part of her "interdisciplinary" disease - depending on who she was currently caring for and what knowledge the health professional have had about her PNES and about PNES generally. Useful information in sent care coordination letter didn't reduce only amount of hospitalisation but also improve to accessibility of psychotherapeutic treatment. Psychotherapeutical treatment is often hampered by frequent questioning by doctors not experienced in PNES, which weakens the patient's confidence in the health care system. The psychotherapeutist (psychologist) should know the pitfalls of treating patients with PNES and prevent them by cooperating with doctors specialized in PNES (Pechanová \& Koprrivová 2020).
Care coordination letter in our case study should be simple and effective tool of cooperation between PNES specialist and psychotherapeutist.

\section{CONCLUSION}

Care coordination letter in PNES may significantly reduce the necessity of hospitalisation and iatrogenic interventions of health care worker, improve awareness of PNES issue among health care providers and approve prognosis of (psycho) therapy even at patient with several prognostic factors implicated in unfavorable outcomes.

\section{Acknowledgements: None.}

\section{Conflict of interest: None to declare.}

\section{Contribution of individual authors:}

Katarína Hubčíková \& Tomáš Rakús: study design, data collection, search for literature, writing the paper.

Lucia Bruncvik \& Zuzana Pechanová: study design, data collection.

Jitka Bušková: supervisor of all work.

All authors reviewed the final manuscript and gave their consent for the final version.

\section{References}

1. Alsaadi T, Shahrour TM: Psychogenic Nonepileptic Seizures: Diagnostic Challenges and Treatment Dilemmas. Int J Neurol Neurother 2015; 2:020

2. Altalib HH et al.: Com municating diagnostic certainity of psychogenic nonepileptic seizures - a national study of provider documentation. Epilepsy Behav 2016: 64: 4-8

3. Doss JL et al.: Appendix: Care coordination treatment plans for patients with psychogenic nonepileptic seizures (PNES). In: LaFrance WC, Schachter SC. Gates and Rowan's none-pileptic seizures. 4th ed. 380-382. Cambridge: Cambridge University Press, 2018.

4. Duncan R \& Oto M: Managing psychogenic nonepileptic seizures in patients with comorbid epilepsy. In: LaFrance, WC, Schachter SC (eds.). Gates and Rowans Nonepileptic Seizures. 262-267. Cambridge: Cambridge University Press, 2018

5. LaFrance WC et al.: Management of psychogenic nonepileptic seizures. Epilepsia 2013; 54: 53-67

6. Pechanová \& Koprivová: Špecifiká psychoterapeutickej liečby u pacientov so psychogénnymi neepileptickými záchvatmi. Čes a slov Psychiatr 2020; 116:16-22

7. Ramos JA \& Brull SJ: Psychogenic non-epileptic sei zures in the post-anesthesia recovery unit. Braz J Anesthesiol 2016; 66: 426-429

8. Tolchin B et al.: Long-term adherence with psychiatric treatment among patients with psychogenic nonepileptic seizures. Epilepsia 2018; 59: 18-22

\section{Correspondence:}

Katarína Hubčíková, MD

Department of Neuropsychiatry of Slovac Medical University

in Bratislava and Psychiatric Hospital of Philipp Pinel in Pezinok

Malacká cesta 63, 90218 Pezinok, Slovakia

E-mail:k.hubcikova@gmail.com 